\title{
A linguístiCa laCANIANa COMO ÉGIDE CIENTÍfICA PARA A PRÁtiCa PSICANALÍTICA: CONSIDERAÇÕES DESDE KANT E SEUS JUÍZOS SINTÉTICOS A PRIORI
}

\author{
[LACANIAN LINGUISTICS AS A SCIENTIFIC SUPPORT FOR PSYCHOANALYTIC PRACTICE: \\ CONSIDERATIONS FROM KANT AND HIS SYNTHETIC JUDGMENTS A PRIORI]
}

Allan Martins Mohr * FAE Centro Universitário; Universidade Tecnológica Federal do Paraná, Brasil

\begin{abstract}
Resumo: O intuito deste trabalho é discutir o problema da linguística lacaniana enquanto base científica para a prática psicanalítica. Ato contínuo, a tese que se apresenta é a de que tal linguística pode ser pensada como sustentáculo científico para a psicanálise desde uma aproximação com a matemática pura enquanto ciência que se respalda a partir de juízos sintéticos a priori. Por fim, responde-se afirmativamente ao problema se considerado que a linguística lacaniana, em especial o entendimento da cadeia significante, respeita o mesmo funcionamento da proposta kantiana para as proposições matemáticas.
\end{abstract}

Palavras-chave: Psicanálise; Lacan; Kant; Linguística lacaniana; Juízos sintéticos a priori
Abstract: This paper aims to discuss the problem of Lacanian linguistics as a scientific basis for psychoanalytic practice. Ongoing, the thesis that is presented is that such linguistics can be thought of as a scientific support for psychoanalysis since an approach to pure mathematics as a science that is supported by synthetic judgments a priori. Finally, the problem is positively answered if considered that Lacanian linguistics, especially the understanding of the significant chain, respects the same functioning of the Kantian proposal for mathematical propositions.

KEYwORDS: Psychoanalysis; Lacan; Kant; Lacanian linguistics; $\boldsymbol{A}$ priori synthetic judgments

\section{INTRODUÇÃO}

A princípio, é importante ressaltar que parto da ideia de psicanálise, conforme a podemos compreender a partir da subversão proposta por Jacques Lacan, como uma prática clínica que se sustenta em algumas ciências. Especialmente, concordo com Eidelsztein ao apontar o quarteto "linguística, lógica, topologia e antifilosofia" (EIDELSZTEIN, 2017b, p. 183). Nesse sentido, o problema que se coloca neste artigo é o de cogitar uma dessas ciências, a linguística, conforme fora tomada por Lacan, enquanto basilar para se pensar a psicanálise dentro do grupo de práticas ditas científicas. Restringir-me-ei à linguística enquanto pensada pelo psicanalista francês, portanto aqui denominada linguística lacaniana, por entender que sua estrutura é extremamente similar, senão idêntica, àquela proposta por Immanuel Kant acerca dos juízos sintéticos a priori. Propositalmente, deixo a desejar a análise acerca das outras

* Doutor em Filosofia pela Pontificia Universidade Católica do Paraná. Professor do curso de Psicologia da FAE Centro Universitário e psicólogo da Universidade Tecnológica Federal do Paraná,Câmpus Curitiba.E-mail: allan.mohr@gmail.com 
três ciências.

Posto isto, o objetivo deste trabalho é responder ao seguinte problema: como é possível a linguística lacaniana enquanto base científica para a prática psicanalítica? Ato contínuo, a tese que apresento é a de que a linguística lacaniana e, conseguintemente, o inconsciente estruturado como uma linguagem podem ser pensados como sustentáculo científico para a psicanálise desde uma aproximação com a matemática pura enquanto ciência que se respalda a partir de juízos sintéticos a priori. Para embasar a proposição supra, discutirei oportunamente o seguinte argumento: a estrutura da linguagem como uma cadeia significante, lacanianamente pensada, pode ser conotada tal qual uma fórmula matemática.

Outrossim, percorrerei a seguinte vicissitude para pensar a cientificidade da prática clínica psicanalítica suportada pela linguística lacaniana: inicialmente, tecerei alguns comentários sobre o pensamento de Sigmund Freud acerca do indivíduo e do inconsciente para, em seguida, apresentar a crítica popperiana à psicanálise freudiana enquanto ciência porquanto metafísica. Depois, trabalharei o homem de Jacques Lacan e sua proposta de inconsciente e discutirei a linguística lacaniana para, finalmente, apresentar a sustentação da hipótese em discussão - a lembrar, que a linguística lacaniana com seu inconsciente estruturado como uma linguagem pode ser pensada como base científica para a psicanálise desde uma aproximação com a matemática pura, kantianamente pensada.

\section{O HOMEM E O INCONSCIENTE FREUDIANO E O PROBLEMA DA PSEUDOCIENTIFICIDADE}

Aqui, cabe ressaltar, denoto homem como o objeto da ciência psicanalítica, mais especificamente, como aquela coisa sobre a qual a psicanálise enquanto prática vai condensar seus raciocínios. Freud o chamava individuum, enquanto Lacan, por sua vez, o vai chamar de sujeito ou, por vezes, parlêtre, ser-para-a-morte, desêtre, entre outros a depender da construção realizada no momento. Isso já nos convoca a um questionamento acerca da tentativa de igualar ou aproximar ambos objetos, o da psicanálise freudiana e o da psicanálise lacaniana. Tentativa que entendo sempre frustrada, se recordarmos da hiância entre as duas formas de cognição. Afinal, como sustenta Carmo, "não há uma continuidade entre esses dois autores, mas uma ruptura" (CARMO, 2020, p. 87).

Desde sua Interpretação dos sonhos, ou mesmo antes, até o postumamente publicado Compêndio de psicanálise, Sigmund Freud constrói seu homem como um individuum, um "id psíquico, desconhecido e inconsciente, sobre cuja superfície repousa o ego" (FREUD, 1996, p. 37). Ademais, logo na sequência dessa citação, Freud vai nos apresentar a representação gráfica de seu indivíduo, ou aparelho psíquico, como da ordem de uma esfera, ou melhor, uma "superfície esferóide" (EIDELSZTEIN, 2017 b, p. 210). Nessa representação, vemos claramente a tentativa freudiana de planificar uma estrutura tridimensional.

No mesmo Compêndio, ao escrever sobre o sistema psíquico, podemos ler um sistema pensado "espacialmente não apenas no sentido funcional, mas também [...] no sentido de dissecção anatômica" (FREUD, 1996, p. 33). Com isso, é possível pensar o sistema psíquico, o aparelho psíquico, o indivíduo freudiano como um corpo tridimensional que, apto a ser dissecado, pode ser desmembrado em partes menores e, por conseguinte, possui extensão. Eidelsztein vai nos lembrar que esse indivíduo, enquanto aquilo que é indivisível, é não obstante internamente segmentável. Ou seja, há de se pensar nesse indivíduo como possuindo um núcleo, o Eu, e outras partes, mas que é uma célula fechada, esférica, e diferenciada do mundo externo; mas mantendo um contato com esse meio ambiente por seu pólo perceptivo. Em suas palavras: a noção 
que circunscreve esse indivíduo esférico é o de "um continuum, algo indivisível. Este sujeito [...] está claramente dividido do outro; não dividido em si e dividido do outro; deve ser uma unidade separada do que não é ela. Isso é o indivíduo: indivisível como tal, dividido em relação a seu entorno" (EIDELSZTEIN, 2017a, p. 45).

Pois bem, o que Freud escreve em 1938 confirma essa leitura ao descrever a mente, ou melhor, a vida anímica como "a função de um aparelho ao qual atribuímos extensão espacial e constituição por diversas partes” (FREUD, 2014b, p. 15). E dentro dessa esfera, se for possível dizer, encontra-se o inconsciente: um dos conceitos basilares para a psicanálise. Inconsciente que, a partir da segunda tópica do aparelho psíquico (por volta de 1920), vai poder ser entendido também como um sistema, uma instância, um lugar dentro desse aparelho tridimensional. Esse lugar especial ou província, Provinzen, esse pedaço de terra anímica é chamada Isso e "seu conteúdo engloba o que foi herdado, trazido com o nascimento e [...] constitutivamente estabelecido; especialmente, portanto, as pulsões" (FREUD, 2014b, p. 17).

As pulsões, por sua vez, são alguma coisa que estão localizadas ou que possuem seu registro de nascimento na província do Isso e tais coisas são "forças que supomos existir por trás das tensões motivadas pelas necessidades do Isso" (FREUD, 2014 b, p. 23). Ainda, as pulsões "representam as exigências corporais [körperlichen Anforderungen] feitas à vida anímica" (p. 23). Em resumo, as pulsões são as forças causadas desde processos somáticos num corpo orgânico, körper, que demandam algo ao anímico, à mente. No mais, são da ordem de uma suposição ou, como Freud nomeou em 1915: "um conceito fundamental [...] bastante obscuro" (FREUD, 2014a. p. 17).

Circunscrevendo, portanto, a ideia de um indivíduo possuidor de uma mente pensada tridimensionalmente na qual existiriam forças que demandam movimento lembrando que tais forças são da ordem de uma suposição -, além de outros aspectos, em especial valendo ressaltar o método indutivo do qual se utiliza Freud para a construção da psicanálise, tudo isso possibilita a Karl Popper alcunhar à psicanálise o título de pseudociência, uma metafísica (POPPER, 1980). Para o autor, a psicanálise, juntamente com a psicologia individual de Adler, a teoria da história de Marx e a astrologia, todas essas deveriam ser consideradas metafísicas, ou pseudociências, especialmente por serem indutivistas e irrefutáveis. Sobre a psicanálise, essa crítica poderia ser pensada desde o problema do método clínico, indutivo, utilizado por Freud para construir sua teoria; ou seja, o método clínico pressupõe que, partindo de um caso singular e da repetição daquilo que o clínico lê no caso, a teoria é construída. Esse método científico é justamente o que está sendo questionado por Popper na década de 1920 , porquanto o autor entende que uma teoria científica boa deve ser sempre uma proibição, ou seja, deve se concentrar em restringir um entendimento. É nesse sentido que ele pensa o método hipotético-dedutivo. À distinção do indutivismo, que parte de um conjunto de casos particulares para propor um entendimento universal, a dedução pensa ao inverso, ou seja, restringe, reduz, parte de um conjunto de informações para esmiuçar a proibição última desse conjunto e singularizar uma lei.

Ademais, pensar a psicanálise enquanto metafísica é também entender que, por exemplo, o inconsciente e as pulsões são objetos que não recolhem exemplares empíricos, ou seja, que não possuem correspondentes na realidade. Nesse sentido, metafísica pode ser descrita, tal qual o faz Kant (2014), como um pensamento especulativo; aliás, algo da ordem da suposição. No limite, toda metafísica tem como fim último o conhecimento de um objeto impossível na experiência; além disso, vale dizer que as fontes de seus juízos tampouco podem ser empíricas. Na letra kantiana, encontramos: "seus princípios (aos quais pertencem não apenas suas máximas, mas também seus conceitos básicos) não podem, portanto, ser tirados da experiência" (KANT, 2014, p. 33). Com a crítica popperiana, cogita-se que o inconsciente freudiano e suas pulsões, por exemplo, não poderiam ser derivados, tampouco pensados empiricamente, menos ainda refutados. Uma crítica importante. 


\section{A SubVersão de JacQues Lacan}

Por usa vez, em especial ao que concerne ao homem e ao inconsciente, Jacques Lacan apresenta uma torção tão extensa da lógica freudiana que é impraticável condensar em um único artigo. Não obstante, tentarei apontar alguns aspectos dessa subversão para servir de auxílio à análise da linguística lacaniana, adiante.

Primeiro ponto que gostaria de sinalizar como uma leitura distinta, por parte de Lacan em relação à Freud, é aquilo que concerne ao homem enquanto objeto da psicanálise. Nesse assunto, o homem lacaniano é assaz distinto do individuum freudiano conotado como uma província psíquica. Em Freud, recordemos, há um indivíduo tridimensional, esferóide, internamente dividido porém único em sua relação com o meio externo. Em Lacan, o homem, objeto de sua psicanálise, é pensada de formas distintas. Deixando um pouco de lado os numerosos conceitos que poderíamos apresentar como circunscrevendo o homem lacaniano, a lembrar, parlêtre, manque à être, até mesmo Dasein, opto neste artigo por distinguir o indivíduo freudiano daquilo que normalmente estudamos como o sujeito lacaniano. E, de imediato, é importante recordar que sujet, em francês, pode significar tanto uma pessoa - e, portanto, um indivíduo -, uma relação de sujeição, o elemento gramatical que, em uma frase, exerce uma ação, quanto um "assunto, tema ou matéria" (PIRES, 2020, p. 15).

À vista disso, podemos afirmar que sujeito é o termo utilizado por Lacan para descrever um efeito da linguagem produzido num parlêtre. Vale lembrar, também, a já conhecida fórmula: o sujeito é o que é representado por um significante a outro significante. Destarte, o sujeito do inconsciente é o assunto, como efeito, de existir linguagem e uma fala que vai de A a S - recorde-se o Esquema L (LACAN, 1955). Ainda, enquanto sujeito do significante, ele é aquilo que, "veiculado pelo significante em sua relação com outro significante, [...] deve ser severamente distinguido tanto do indivíduo biológico quanto de qualquer evolução psicológica classificável como objeto da compreensão" (LACAN, 1998d, p. 890).

De toda forma, o sujeito lacaniano é distinguido sobremaneira do indivíduo freudiano. Primeiro, pela diferença entre a tridimensionalidade do aparelho psíquico de Sigmund Freud e o sujeito como efeito de discurso em Jacques Lacan; mas também pelo fato de que, enquanto tridimensional e esférico, o indivíduo freudiano é uma célula distinta do mundo externo, ao passo que o sujeito lacaniano não o é. E isso porque o sujeito enquanto uma função discursiva precisa ser pensado desde uma perspectiva topológica e a figura que vai lhe caber é justamente a da Banda de Moebius: uma fita que, por meio de uma torção, ao ter costuradas suas duas extremidades, produz-se como uma figura superficial de apenas um lado. E como isso funciona para o sujeito? Bem, sujeito e A (grande Outro) são como a banda, dois de uma mesma superfície, impossibilitando, com isso, pensar um sujeito externo ao ambiente, distinto do Outro, lugar da Outra cena. Até porque, vale lembrar, o sujeito é um efeito da existência da fala, proveniente de A, do grande Outro, lugar do tesouro do significante; lugar desde onde recebe sua mensagem de forma invertida. Nas palavras do próprio Lacan, em 1972, encontramos que o sujeito é ex-sistência e que "essa ex-sistência é dizer, e o comprova por ficar o sujeito à mercê de seu dito, quando ele se repete; ou seja, ao encontrar aí, como a banda moebiana, seu fading (esvaecimento)" (LACAN, 2003, p. 487).

O sujeito ex-siste desde Outro lugar, provêm de A, é efeito de haver dito. Por consequência, o inconsciente do qual o sujeito é sujeito, tem por condição a linguagem (LACAN, 2003).

Se o inconsciente de Freud era sistêmico, dinâmico e econômico, o inconsciente lacaniano é discursivo. Ele é "a parte do discurso concreto, como transindividual, que falta à disposição do sujeito para restabelecer a continuidade de seu discurso consciente" (LACAN, 1998a, p. 260); mais, "é o capítulo de minha história que é 
marcado por um branco ou ocupado por uma mentira: é o capítulo censurado" (1998a., p. 260); ainda, é a sua própria história proveniente de Outro lugar, afinal: "o inconsciente do sujeito é o discurso do Outro [l'Autre]" (1953, p. 16, tradução do autor). Nesse sentido, o inconsciente é isso que falta ao sujeito para completar sua história; história essa que é construída desde Outro lugar por meio da linguagem, por meio dos significantes. Até porque, com Lacan, a história individual e o universo como um todo só pode existir dentro e por meio da linguagem. Portanto, o inconsciente entra nessa lógica de um discurso transindividual no sentido de que ele é um capítulo da história construída a partir do Outro e direcionada, discursivamente, a um sujeito.

Após essas considerações iniciais acerca da distinção indivíduo-sujeito e do inconsciente em Freud e Lacan, a fim de argumentar sobre a linguística lacaniana enquanto similar à matemática, cabe justamente tecer considerações sobre essa linguagem enquanto estrutura que antecede o sujeito e sustenta, conforme entendeo, a psicanálise lacaniana. De imediato, vale recordar o que diz o psicanalista francês em Posição do inconsciente: "o efeito de linguagem é a causa introduzida no sujeito. [...] Mas esse sujeito é o que o significante representa, e este não pode representar nada senão para um outro significante" (LACAN, 1998c, p. 849) e, justamente por isso, não se fala com o sujeito, ele é falado por Isso.

\section{BREVE RECORTE DA LINGUÍSTICA LACANIANA}

É notório que Jacques Lacan, ao construir sua linguística, apoia-se principalmente em dois autores, Ferdinand de Saussure e Roman Jakobson. Frugalmente falando, do primeiro, Lacan se apropria e subverte a noção de significante e significado e, do último, toma conceitos tais como código, mensagem e shifter. Neste trabalho, iremos nos ater ao problema do significante e do significado.

Primeiramente publicado em 1916, o Curso de Lingüística Geral de Saussure é uma versão estabelecida por seus alunos dos cursos ofertados pelo linguista nos anos de 1907, 1908 e 1910. Na obra publicada postumamente, o docente nos explica que a língua é "um sistema de valores puros" (SAUSSURRE, 2006, p. 130) e pode ser descrita como "a totalidade das imagens verbais armazenadas em todos os indivíduos" (2006, p. 21) de uma mesma comunidade ou que compartilham a mesma língua. A essa totalidade, Saussure vai chamar de tesouro, porquanto "trata-se de um tesouro depositado pela prática da fala em todos os indivíduos pertencentes à mesma comunidade, um sistema gramatical que existe virtualmente em cada cérebro ou, mais exatamente, nos cérebros dum conjunto de indivíduos" (2006, p. 21). Nesse sentido, em nenhum cérebro ou em nenhum indivíduo se localiza a língua completa, ela só pode ser encontrada, por assim dizer, enquanto totalidade, na massa.

Agora, essa língua é formada por signos linguísticos que, para o autor, é a união entre um conceito e uma imagem acústica. A imagem acústica, que podemos também chamar de significante, é "a impressão (empreinte) psíquica desse som, a representação que dele nos dá o testemunho de nossos sentidos; tal imagem é sensorial" (SAUSSURE, 2006, p. 80). Por outro lado, o conceito, também chamado significado, é algo de mais abstrato, à distinção de certa materialidade destinada à imagem sensorial, diz Saussure. De qualquer maneira, ao propor um esquema gráfico para o signo linguístico, Saussure escreve o Conceito acima de uma barra sob a qual encontramos a Imagem acústica, ambos dentro de um círculo fechado com flechas apontando, uma para cima, à esquerda e fora do círculo, e outra para baixo, à direita e também fora do círculo. 


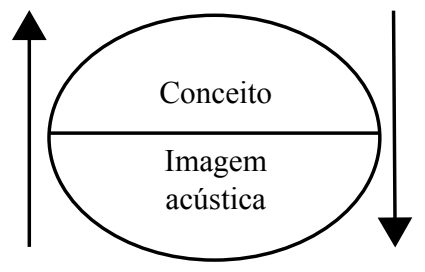

“O signo linguístico" (SAUSSURE, 2006, p. 80).

Há uma subversão, senão uma inversão da lógica apresentada por Saussure na linguística lacaniana. Para o psicanalista francês, o que deve vir acima da barra é o Significante, enquanto o significado vem abaixo dela: S/s. Não obstante, para Lacan a linguagem é a lei estruturante do ser humano, o que equivale a dizer que tudo o que é da ordem do humano só existe na e pela linguagem e, ainda, afirma de inúmeras maneiras que "é o mundo das palavras que cria o mundo das coisas" (LACAN, 1998a, p. 277). Nesse sentido, isso é equivalente ao que Saussure vai chamar de valores puros do sistema chamado língua, porquanto anterior à qualquer experiência. É tal sistema que antecede as coisas concretas. Puro, aqui, também veremos em Kant, remete-nos ao $a$ priori de toda e qualquer empiria.

Pois bem, para Lacan, o símbolo enquanto pacto social por meio da linguagem é o que faz o homem e permite com que esse homem possa falar. E a maneira como tudo isso se articula é a partir de uma cadeia significante. Ademais, "os símbolos efetivamente envolvem a vida do homem numa rede tão total que conjugam, antes que ele venha ao mundo, aqueles que irão gerá-lo 'em carne e osso'; trazem em seu nascimento, com os dons dos astros, senão com os dons das fadas, o traçado de seu destino" (LACAN, 1998a, p. 280). Posto isso, cabe ainda dizer que o autor vai entender a linguagem também por meio da banda de Moebius, no sentido de que o emissor, aquele do qual parte a mensagem, vai receber do receptor essa mesma mensagem de forma invertida, como que retornando de uma mesma superfície borromeana. Se recordarmos o Esquema $\mathrm{L}$ em seu eixo simbólico $(\mathrm{A} \rightarrow \mathrm{S})$, a mensagem retorna do Outro porquanto é o Outro quem a pontua (EIDELSZTEIN, 2017a).

Nesse sentido, com a linguística lacaniana temos a ideia de que o significante como elemento puro, logicamente a priori de qualquer experiência porque criador do mundo objetivo, articula-se a outro significante para produzir algum significado, frase ou sentido. No limite, o significante é o elemento irredutível da língua e da linguagem com o qual se produz um sujeito e o mundo humano. Até porque, diz Lacan: "um sujeito [é] definido por sua articulação pelo significante" (LACAN, 1998b, p. 819), uma articulação em cadeia, a cadeia significante: $S_{1}-S_{2}-S_{3} \ldots S_{n}$.

Ainda sobre o significante, Lacan diz que ele se constitui apenas pela diferença, ou ainda, oposição sincrônica com outros significantes, e vai chamar de A, grande Outro, o "lugar do tesouro do significante" (LACAN, 1998b, p. 820). Recordemos que o próprio Saussure chamou de tesouro o lugar da "totalidade das imagens verbais" (SAUSSURE, 2006, p. 21) recorrendo à imagem de um cérebro das massas para pensar tal localidade. Lacan, por sua vez, usa uma letra - preferiu, quiçá, abandonar o apelo ao organismo e sustentar seu lugar do tesouro na própria língua. Enfim, A é o lugar do tesouro do significante, lugar onde se encontra a totalidade daquilo que é possível existir em termos de significantes que se reconhecem ou, melhor, constituem-se "por uma reunião sincrônica e enumerável, na qual qualquer um só se sustenta pelo princípio de sua oposição a cada um dos demais" (LACAN, 1998b, p. 820).

Antes de encerrarmos esta parte do ensaio, cabe ainda reforçar que, segundo Lacan, o significante é insignificante, no sentido de que não significa nada, mas apenas sua articulação pode gerar um significado. E, também, que esse A, enquanto Outro, 
deve ser entendido "como sítio prévio do puro sujeito do significante, [portanto] ocupa a posição mestra, de dominação, antes mesmo de ter acesso à existência" (LACAN, 1998b, p. 821), ou seja, que o Outro, A, é onde se localiza o verdadeiro sujeito do significante enquanto puro, a priori de qualquer experiência. E, justamente porque o Outro é o lugar de onde partem os significantes que criam o universo humano, é possível para Lacan afirmar que "não existe metalinguagem que possa ser falada, ou, mais aforisticamente, que não há Outro do Outro" (1998b, p. 827). Em outras palavras, nada há no universo, sempre universo humano, que esteja fora da linguagem; linguagem articulada por meio de significantes.

\section{A CRítica Kantiana e a MATEMÁtica PURA}

Em 1781, Kant publica a Crítica da Razão Pura e, em 1783, seu Prolegômenos a qualquer metafisica futura que possa apresentar-se como ciência. Em ambas as obras, o filósofo vai se propor, entre outras inumeráveis questões, a discutir a possibilidade da matemática pura, ou seja, questionar como é possível pensar a matemática enquanto ciência a partir de uma cognição pura, precedente a toda e qualquer experiência. É essa discussão, principalmente, que tomarei dos Prolegômenos com o intuito de sustentar a tese de que a linguística lacaniana pode ser pensada como sustentáculo científico para a psicanálise desde uma aproximação com a matemática pura enquanto ciência que se respalda a partir de juízos sintéticos a priori.

Inicialmente cabe destacar que o problema com o qual Kant se encontra desde o início dos Prolegômenos, e que já se encontrava na Crítica da Razão Pura, é justamente pensar a razão pura e os critérios para se cogitar uma ciência enquanto válida; por conseguinte, se poderíamos chamar a metafísica de ciência. Com isso, Kant se propõe estudar a razão enquanto aquela que se ocupa com o puro pensamento e "determinar, de maneira completa e segundo princípios universais, toda a extensão da razão pura” (KANT, 2014, p. 29). Vale ratificar que o caráter puro da razão se refere à antecedência de toda empiria, ou seja, uma razão a priori.

Sobre a matemática pura e a razão matemática, o filósofo vai dizer que essa ciência possui as fontes de sua cognição a priori de toda e qualquer experiência sendo necessário entender que ela atua por meio de juízos sintéticos a priori. Não obstante, cabe, inicialmente e no rastro de Kant, distinguir dois tipos de juízos: os juízos analíticos e os juízos sintéticos.

Os juízos analíticos atuam sustentados unicamente no princípio de contradição, constituem algo como a substância de um conceito e são apoditicamente a priori. Ou seja, os juízos analíticos são raciocínios que obrigatoriamente já estão no sujeito antes de qualquer predicado e o predicado nada acrescenta ao conceito no sujeito, são, portanto, explicativos (KANT, 2014). Por sua vez, os juízos sintéticos podem ser $a$ posteriori ou não. Os juízos sintéticos a posteriori possuem sua origem na experiência, são empíricos, até porque "seria um disparate fundamentar um juízo analítico na experiência, já que não é preciso ir além de meu conceito para emitir o juízo" (2014, p. 35). Distintamente, os juízos sintéticos a posteriori precisam da experiência para, somando-se uns aos outros, aumentar, ampliar conhecimento.

Ora, o que diz Kant é que ainda há os juízos sintéticos a priori; e esses nos interessam sobremaneira. Diz ele que é justamente esse tipo de juízos os pertencentes à matemática pura. São sintéticos porquanto se relacionam necessariamente uns com os outros e adicionam conhecimento, porém são anteriores à experiência. Nesse sentido, diz-nos Kant que as "proposições matemáticas genuínas são sempre juízos a priori e não empíricos, porque trazem consigo necessidade, algo que não pode ser obtido da experiência" (KANT, 2014, p. 36). Um dos exemplos que nos apresenta o filósofo é a da proposição $7+5=12$. Diz ele que frente à proposição dada, poder-se-ia pensar que 
ela fosse uma proposição analítica, no sentido de entender que a soma de sete com cinco, pelo princípio de contradição, é doze e não é não-doze, o que implicaria sua analiticidade. Contudo, explica que o resultado, o conceito dessa soma, sete com cinco, não pressupõe um resultado concreto, "não contém nada além da união dos dois números em um único" (2014, p. 36), o que não implica a necessidade disso ser um 54 número dado, doze no caso. Ou seja, $7+5$ é igual a um número, a um puro conceito que não implica a ideia concreta, empírica de doze. Diz Kant que "o conceito de doze não está de modo algum já pensado quando penso simplesmente essa união de sete e cinco, e por mais que analise meu conceito dessa possível soma, não encontrarei ali o número doze" (2014, p. 36). Por isso podemos, sem prejuízo, reescrever a proposição da seguinte maneira: $5+7=\mathrm{C}$ ou, ainda, $\mathrm{A}+\mathrm{B}=\mathrm{C}$.

Portanto, "por mais que viremos e reviremos nosso conceito, sem o auxílio da intuição e apenas pela análise de nossos conceitos jamais poderíamos encontrar a soma" (2014, p. 36-37). Contudo, o próprio Kant diz que algumas proposições matemáticas podem ser compreendidas como analíticas, por exemplo, algumas proposições fundamentais sustentadas pelos geômetras, contudo, "enquanto proposições de identidade, servem apenas como elos na cadeia do método, e não como princípios, por exemplo, a = a" (2014, p. 37). Ou seja, algumas proposições, como as de identidade, 7 $=7$ e $5=5$, são analíticas, mas não podem ser entendidas como princípios da matemática pura; enquanto, por sua vez, os princípios serão sempre sintéticos e $a$ priori. Até porque "o que é essencial e distintivo da pura cognição matemática em relação a todas as demais condições a priori é que ela deve proceder inteiramente, não a partir de conceitos, mas sempre apenas pela construção de conceitos" (2014, p. 3738), e construção é sempre sintética.

Bem, o que compreendo, então, é que para Kant a matemática funciona a partir de juízos sintéticos a priori, ou seja, suas construções, apesar de possuírem conceitos intuitivos analíticos, $7=7$, são sempre da ordem da construção de novos conceitos, tal qual a soma de sete e cinco. Contudo, o resultado da proposição nunca será algo substancial, no sentido de essência, analítico, explicativo em si, mas o resultado de uma proposição será sempre algo não essencial, tampouco sensível, mas um resultado que não se encontra no sujeito, é algo novo, portanto sintético. Ademais, tudo isso se dá antes da experiência, antes da coisa concreta, antes dos objetos no mundo. Ou seja, há a proposição $5+7=12$ antes mesmo de haver maçãs para serem contadas: cinco maçãs com sete maçãs, são doze maçãs.

Mas então, tal qual se pergunta Kant, "como são possíveis proposições sintéticas a priori?" (KANT, 2014, p. 47). São possíveis pois as ciências que trabalham a partir desse pressuposto, a ciência pura da natureza e a matemática pura, apresentam seus objetos, os objetos de suas ciências, na intuição, a priori; e só depois se relacionam a objetos concretos. Em outras palavras, os objetos da matemática pura, para usar a ciência que elegemos estudar neste trabalho, a matemática pura trabalha com objetos intuitivos, anteriores à experiência. Ela, a matemática, é um "domínio de cognições [...] traz consigo uma certeza inteiramente apodítica, ou seja, necessidade absoluta, e não tem, portanto, seu fundamento na experiência, é um puro produto da razão e além disso é inteiramente sintético" (2014, p. 53). Kant ainda nos explica que a matemática primeiro demonstra o conceito intuitivamente, a priori, em uma intuição pura, o que implica dizer que seus pensamentos sempre são intuitivos. Agora, como seria possível algo tal como uma intuição a priori? Diz-nos o filósofo que tal construção, uma intuição anterior à experiência do objeto real, é possível "se ela contém nada mais que a forma da sensibilidade, que em mim, enquanto sujeito, precede todas as impressões reais com que sou afetado por objetos" (2014, p. 55). Tal sensibilidade, podemos dizer, é a faculdade, ou melhor, a capacidade de um sujeito, por meio intuição, perceber os aparecimentos, Erscheinungen.

Não é a sensibilidade corpórea ou o reconhecimento dos objetos externos por 
meio dos órgãos do sentido, isso já seria algo a posteriori, mas essa sensibilidade é a faculdade de apreender dos aparecimentos antes da possibilidade de se experimentar os objetos concretos, reais. Assim nos explica Kant: há uma intuição pura que é "a mera forma da sensibilidade que precede o aparecimento real de objetos, na medida em que ela é o que, em primeiro lugar o torna possível" (2014, p. 57). Continua o autor: "essa faculdade de intuir a priori não diz respeito à matérias do aparecimento, isto é, àquilo que nele é sensação, pois esta constitui o empírico, mas apenas à sua forma, espaço e tempo" (2014, p. 57). Haveria no sujeito qualquer coisa que podemos nomear intuição, enquanto mecanismo duplo de apreensão dos aparecimentos. Tal intuição pura pode ser externa ou interna. A forma externa da intuição é o espaço, quanto sua forma interna, o tempo.

Agora, outro ponto de singular importância é entender que essa apreensão dos aparecimentos é o que torna possível, em um momento outro, o objeto enquanto concretude. Assim, os juízos sintéticos a priori da matemática pura são possíveis apenas porque se referem à intuição pura (tempo e espaço), que se relaciona aos aparecimentos e que precedem a experiência real do objeto. Assim, a matemática pura diz respeito "a simples aparecimentos, e só [pode] representar ou aquilo que torna possível a experiência em geral, ou aquilo que [...] deve sempre poder ser representado em alguma experiência possível" (KANT, 2014, p. 91).

Portanto, assim é possível a matemática pura, e assim ela se sustenta como ciência; ressaltando que suas cognições são sintéticas a priori e seus aparecimentos torna possível, ulteriormente, a experiência. No limite, é essa intuição pura (espaço e tempo) que torna possível o objeto, uma vez que "a experiência consiste na conexão sintética de aparecimentos (percepções) em uma consciência” (KANT, 2014, p. 81). E isso, cabe lembrar, a distingue da metafísica, pois essa última não possui objeto de estudo correspondente na realidade (Deus, alma, imortalidade) e suas proposições não são provadas pelos princípios da razão, da razão pura, ou seja, a priori. Suas proposições, afirma Kant (2014), são analíticas e nada dizem, ou dizem pouco acerca de um aditamento de conhecimentos.

\section{A CAdeia Significante e as Proposições matemáticas}

$\mathrm{Na}$ Introdução deste artigo, disse que, para sustentar nossa hipótese de trabalho, desenvolveria oportunamente o argumento de que a estrutura da linguagem conforme pensada por Jacques Lacan, ou seja, como uma cadeia significante, poderia ser conotada tal qual uma fórmula matemática. É, pois, chegado o momento de desenvolver tal raciocínio que, no final das contas, tem por proposta aproximar o " $5+7$ $=12$ " kantiano, da cadeia significante " $\mathrm{S}_{1}-\mathrm{S}_{2}-\mathrm{S}_{3}-\mathrm{S}_{4}-\mathrm{S}_{5}$ ", de Lacan. Não obstante, antes de ratificar minha elaboração, algumas considerações podem servir para esmiuçar o raciocínio que tomo de partida para essa tarefa.

Ainda nos Prolegômenos, diz Kant que “"todos os princípios sintéticos a priori nada mais são que princípios de experiência possível', e jamais podem se referir a coisas em si mesmas [noumena], mas apenas a aparecimentos [Erscheinungen] enquanto objetos da experiência" (KANT, 2014, p. 91). Além do mais, ainda afirma que a matemática pura, como consequência do exposto, só pode dizer respeito a aparecimentos e pode apenas "representar ou aquilo que torna possível a experiência em geral, ou aquilo que, na medida em que se deriva desses princípios, deve sempre poder ser representado em alguma experiência" (2014, p. 91). Lembrando que princípios são a alcunha postulada às regras que, por não apresentarem nenhuma outra regra acima que pudessem dela proceder, são necessárias, e que essas regras são a simples premissa da junção de representações em uma consciência, ou seja, os juízos, esses princípios sintéticos e a priori, portanto decomposição dos juízos de mesma 
índole, dizem respeito apenas à possibilidade de uma experiência. Ou seja, os princípios matemáticos, as regras e os juízos da matemática dizem respeito à uma possibilidade de experiência, nunca se referindo à coisa em si.

Os juízos sintéticos a priori, tal qual a preposição $5+7=12$, não se relacionam a uma experiência, mas criam a possibilidade de uma experiência; mais além, essa preposição enquanto juízo se refere a um aparecimento que é da ordem daquilo que se vincula a uma intuição e é pressuposto ser justamente aquilo que possibilita a experiência em si ou, quiçá, algo que será representado na experiência. Afirma Kant que a experiência em si mesma, o empírico, se deriva, procede, emana do juízo: "o entendimento não extrai suas leis (a priori) da natureza, mas as prescreve a ela" (KANT, 2014, p. 98). O entendimento, cuja função é associar representações naquilo que se denomina consciência, prescreve, dita as regras à natureza. Assim, a experiência não precede o entendimento, tampouco a intuição ou o juízo. $\mathrm{O}$ entendimento, "ao construir ele próprio a figura [geométrica] de acordo com seus conceitos [...], insere nela a lei” (2014, p. 99).

Pois bem, a matemática pura funcionaria, apressadamente falando, a partir da seguinte construção: há no homem uma capacidade sensível de perceber o mundo, não enquanto coisas mesmas, noumena, mas que o alcança (o mundo) como aparecimentos, Erscheinungen; desses aparecimentos, derivam-se representações que, associadas, são denominadas pensamento ou juízo; esse juízo pode ser analítico ou sintético, conforme já discutimos anteriormente; um pensamento no qual se subsome as percepções $a$ priori, anteriores a qualquer experiência, é denominado conceito puro do entendimento; e, finalmente, os juízos como condição para a associação das representações em uma consciência são denominados regras, e elas, "na medida em que representam a união como necessária, são regras a priori, e, na medida em que não há outras regras acima delas das quais pudessem se derivar, são princípios" (KANT, 2014, p. 82).

A matemática pura atua com juízos sintéticos a priori, o que significa dizer que suas construções são necessárias e criadoras da experiência. Seus conceitos e proposições são anteriores à empiria, ainda mais especificamente, o conceito, a intuição matemática cria o objeto da matemática. Ainda com Kant, lemos: "as condições a priori da possibilidade da experiência são ao mesmo tempo as fontes das quais todas as leis universais da natureza devem ser derivadas" (KANT, 2014, p. 73). E quais essas condições? A existência de uma cognição, um pensamento, além de juízos a priori e notadamente sintéticos. Afinal, "a possibilidade da experiência [...] se baseia em conceitos puros do entendimento" (2014, p. 78).

Aqui ponho a questão que, entendo, cinge inicialmente a matemática pura tal qual pensada por Kant nos Prolegômenos com a linguística lacaniana enquanto uma tentativa de embasar cientificamente a psicanálise e que nos permitirá avançar: proponho aproximar, porventura igualar "a condição a priori da possibilidade da experiência" (KANT, 2014, p. 73) com o grande Outro, A. Até porque, vale lembrar, o eixo simbólico sai de A, enquanto causa, e vai até S, o efeito.

Em 1953, Lacan afirmou que "é o mundo das palavras que cria o mundo das coisas" (LACAN, 1998a, p. 277), o que convoca a entender que a linguagem, a fala, o dito e as palavras, enfim a cadeia significante é anterior aos objetos empíricos; mais, ainda, o universo de linguagem é a substância da qual derivam os objetos concretos; para ser mais exato, e recordando o que nos propõe o psicanalista em seu Seminário de 1972-1973, os significantes são, inclusive, a causa material dos corpos (LACAN, 19721973/inédito). Então, se as coisas são causadas, coagidas à existência, criadas pela linguagem, pelas palavras, pelos significantes, o lugar de onde provêm esses significantes pode ser entendido como a condição sine qua non da possibilidade de existência da experiência. Portanto, o grande Outro, A, tesouro do significante, logra ser compreendido como essa condição, uma vez que d'Ele deriva a estrutura necessária da existência de toda extensão; uma estrutura de linguagem. 
A proposição matemática desenvolvida por Kant, $7+5=12$, pensada como uma cadeia de cinco significantes permite compreender que os juízos sintéticos a priori são um entendimento plausível para a linguística lacaniana; até porque Lacan entende os números como símbolos puros ou, se for possível, pura forma, significantes radicais. Duas citações do mesmo texto de 1953 me ajudam a desenvolver essa ideia: a primeira diz que "o homem fala, pois, mas porque o símbolo o fez homem. [...] as leis do número, isto é, do símbolo mais purificado, revelam-se imanentes ao simbolismo original" (LACAN, 1998a, p. 278). Ou seja, para Lacan, o homem deve ser entendido como criado desde Outro lugar, por meio dos significantes do Outro, por meio do símbolo; e as leis do número - as leis/regras da matemática pura enquanto simples premissas da junção de representações em uma consciência, em outras palavras, os juízos - devem ser compreendidas como sendo inerentes ao simbolismo original, ao tesouro do significante. Em outras palavras, a lei dos números da qual fala Lacan, a lei concernente ao símbolo mais purificado, essa que é intrínseca à ordem simbólica, é a regra da associação das representações (Kant) ou dos significantes (Lacan) em uma consciência, os juízos. Mas não qualquer juízo, senão aquele que diz respeito à matemática pura: um juízo sintético a priori. A segunda citação ratifica a primeira: “a matemática pode simbolizar um outro tempo, notadamente o tempo intersubjetivo que estrutura a ação humana" (LACAN, 1998a, p. 288). Lembrando que aqui, em 1953, intersubjetivo diz respeito à relação $\mathrm{A} \rightarrow \mathrm{S}$.

Se ainda for pertinente aprofundar outro aspecto relacionado à comparação entre a matemática conforme pensada por Kant em seus Prolegômenos e a linguística lacaniana, é preciso pensar acerca da insignificância do número e do significante. Diz Kant que "não há nenhuma intuição fora do campo da sensibilidade, esses conceitos puros estão desprovidos de todo significado, na medida em que não há nenhum meio de exibi-los in concreto" (KANT, 2014, p. 94). Em outras palavras, a intuição enquanto forma da sensibilidade aceder e receber o mundo, por assim dizer, não existe fora do seu campo, o da sensibilidade. Isso faz com que os conceitos puros, necessariamente provenientes de uma lógica intuitiva (tempo e espaço), não possuam significado, uma vez que eles são formulados antes da experiência, previamente a qualquer concretude, $a$ priori de toda extensão. Assim também funcionam os significantes: enquanto pura forma (pura porque a priori e forma porque ausente de conteúdo), não significam nada e os próprios significados são apenas associações possíveis, dentre outras, de alguns significantes. Sozinho, um significante é tal como o "7" da proposição kantiana; ele é sabido ser porque diferente dos demais, mas seu significado, seu valor só é adquirido na relação, na associação com outros. A cadeia significante também é, nesse sentido, a priori de qualquer experiência concreta, ela cria a experiência concreta; e é sintética porquanto um significante não se sustenta por si mesmo (analiticidade), mas depende de um encadeamento para ter algum valor.

\section{CONSIDERAÇÕES FINAIS}

Percorrido esse caminho, cabe recolocar a pergunta inicial deste artigo: afinal, é possível pensarmos a linguística proposta por Jacques Lacan como um dos sustentáculos científicos da prática psicanalítica? Apesar de não ter pretendido aqui esgotar o problema, senão apontar algumas elaborações, entendo que pude responder afirmativamente à questão se considerarmos que a linguística lacaniana, em especial o entendimento da cadeia significante, respeita o mesmo funcionamento da proposta kantiana dos juízos sintéticos a priori para a matemática pura.

Vale ainda, com o intuito de finalizar, lembrar que para falarmos ou descrevermos uma fórmula matemática só a podemos fazer utilizando significantes que, ajuntados, nos dão palavras. Até porque a matemática é uma coisa do mundo humano e 
"as coisas do mundo humano são coisas de um universo estruturado em palavras, [...] a linguagem, que os processos simbólicos dominam, governam tudo" (LACAN, 2008, p. 59).

Por fim, o que cuidei de elaborar nesse artigo foi uma aproximação entre um entendimento pontual da linguística lacaniana com a descrição kantiana dos juízos sintéticos a priori; juízos esses enquanto sustentáculo do entendimento científico da matemática pura, à distinção da metafísica. Por conseguinte, propus pensar tal associação com o intuito de apontar um caminho possível de compreensão da referida linguística como égide científica para a prática psicanalítica. Entendo que tal objetivo foi satisfeito, não obstante compreendo também a impraticabilidade de sustentar a cientificidade da psicanálise com este trabalho e a necessidade de tantas outras discussões.

\section{REFERÊNCIAS}

CARMO, Jessika Gomes do. O inconsciente como coisa e o inconsciente como estrutura de linguagem: diferenças teórico-epistemológicas entre Freud e Lacan. Revista Borda, v. 1, n. 1, 2020. Disponível em: https://bordalacaniana.com. Acesso em 26 nov. 2020.

EIDELSZTEIN, Alfredo. O grafo do desejo. São Paulo: Toro Editora, 2017a.

EIDELSZTEIN, Alfredo. Otro Lacan. Buenos Aires: Letra viva, $2017 \mathrm{~b}$.

FREUD, Sigmund. (1923). O ego e o id. In: FREUD, Sigmund. Obras psicológicas completas de Sigmund Freud: edição standard brasileira (vol. XIX). Rio de Janeiro: Imago, 1996.

FREUD, Sigmund. (1915). As pulsões e seus destinos. Belo Horizonte: Editora Autêntica, 2014a.

FREUD, Sigmund. (1940 [1938]). Compêndio de Psicanálise. In: FREUD, Sigmund. Compêndio de Psicanálise e outros escritos inacabados. Belo horizonte: Editora Autêntica, 2014b.

KANT, Immanuel. Prolegômenos a qualquer metafísica futura que possa apresentar-se como ciência. São Paulo: Estação Liberdade, 2014.

LACAN, Jacques. (1953). Fonction et champ de la Parole et du Langage... Relatório do Congresso de Roma, Instituto de Psicologia da Universidade de Roma, 26 a 27 de setembro de 1953. Disponível em: https://staferla.free.fr. Acesso em 27 nov. 2020.

LACAN, Jacques. (1955). Le moi, 1955. Disponível em: https://staferla.free.fr. Acesso em 27 nov. 2020.

LACAN, Jacques. (1953). Função e campo da fala e da linguagem em psicanálise. In: LACAN, Jacques. Escritos. Rio de Janeiro: Zahar, 1998a.

LACAN, Jacques. (1960). Subversão do sujeito e dialética do desejo no inconsciente freudiano. In: LACAN, Jacques. Escritos. Rio de Janeiro: Zahar, 1998b.

LACAN, Jacques. (1960-1964). Posição do inconsciente. In: LACAN, Jacques. Escritos. Rio de Janeiro: Zahar, 1998c.

LACAN, Jacques. (1966). A ciência e a verdade. In: LACAN, Jacques. Escritos. Rio de Janeiro: Zahar, 1998d.

LACAN, Jacques. (1972). O aturdito. In: LACAN, Jacques. Outros escritos. Rio de Janeiro: Jorge Zahar Ed., 2003.

LACAN, Jacques. (1972-1973). Encore. 1972-1973/inédito. Disponível em: http://staferla.free.fr. Acesso em 01 dez. 2020.

LACAN, Jacques. (1959-1960). Seminário, livro 7: a ética da psicanálise. Rio de Janeiro: Jorge Zahar Ed., 2008.

PIRES, Introdução ao sujeito do inconsciente. Revista Borda, v. 1, n. 1, 2020. Disponível em: https://bordalacaniana.com. Acesso em 27 nov. 2020.

POPPER, Karl R. Conjecturas e Refutações. Brasília: Editora da UnB, 1980.

SAUSSURE, Ferdinand de. Curso de lingüística geral. São Paulo: Cultrix, 2006. 